\title{
The Impact of Coronavirus Disease 2019 (COVID-19) on Retinal Microcirculation in Human Subjects
}

\section{Auswirkungen der Coronavirus-Krankheit 2019 (COVID-19) auf die retinale Mikrozirkulation bei Menschen}

Authors

Emre Aydemir ${ }^{1 \mathbb{D}}$, Gozde Aksoy Aydemir ${ }^{1 \mathbb{D}}$, Halil Ibrahim Atesoglu², Yasin Sakir Goker ${ }^{2}$, Kazim Caglar Ozcelik $^{3}$, Hasan Kiziltoprak ${ }^{1}$

Affiliations

1 Ophthalmology Department, Adıyaman University Training and Research Hospital, Adıyaman, Turkey

2 Ophthalmology Department, Ulucanlar Eye Training and Research Hospital, Ankara, Turkey

3 Surgical Oncology Department, Yıldırım Beyazıt University, Ankara, Turkey

\section{Key words}

coronavirus disease 2019, retinal vascular structures, optical coherence tomography angiography, vessel density, retinal microcirculation

\section{Schlüsselwörter}

Coronavirus-Krankheit 2019, Netzhautgefäßstrukturen, Gefäßdichte, retinale Mikrozirkulation, optische Kohärenztomografieangiografie

\section{received}

20.5. 2021

accepted

30.7. 2021

published online

$$
\text { 29.9.2021 }
$$

\section{Bibliography}

Klin Monatsbl Augenheilkd 2021; 238: 1305-1311

DOI 10.1055/a-1579-0805

ISSN 0023-2165

(c) 2021. Thieme. All rights reserved.

Georg Thieme Verlag KG, Rüdigerstraße 14,

70469 Stuttgart, Germany

\section{Correspondence}

Dr. Emre Aydemir

Adiyaman Universitesi Egitim ve Arastirma Hastanesi, Ophthalmology

Adiyaman, 02200 Adiyaman, Turkey

Phone: + 90 (0) 5307002440 , Fax: + 90 (0) 4162101015

md_emre_aydemir@hotmail.com

\section{ABSTRACT}

Background The aim of the study was to assess retinal microcirculation in patients with coronavirus disease 2019 (COVID-19) through the use of optical coherence tomography angiography (OCT-A) and compare the results with those obtained in healthy controls.

Methods The study enrolled 39 patients who had fully recovered from COVID-19 and 40 healthy controls. OCT-A image acquisitions were obtained using AngioVue software (version 2017.1.0.151) and the RTVue XR Avanti imaging system (Optovue Inc., Fremont, CA, USA). Nonflow area in the superficial capillary plexus (SCP), foveal avascular zone (FAZ) area in the whole retinal vasculature, FAZ perimeter, acircularity index of FAZ, and foveal density were automatically obtained with the FAZ assessment tool. Vessel density (VD) at the SCP and deep capillary plexus were also measured.

Results Compared to the control group, the nonflow area and the FAZ area in the whole retina was greater in the COVID-19 group; however no statistically significant difference was observed ( $p>0.05$ respectively). As for vessel densities, all superficial parafoveal VD parameters were considerably higher in the COVID-19 group compared to the control group ( $p<0.05$ respectively). Despite the fact that the vessel densities in the remaining zones were lower in the COVID-19 group, those differences were not statistically significant ( $p>0.05$ respectively).

Conclusion VD at the parafoveal area of the SCP was significantly higher among patients in the late post-recovery period of COVID-19 disease compared to healthy controls. These findings show the impact of COVID-19 on the retinal microvasculature and its possible role as a risk factor for the development of ocular diseases.

\section{ZUSAMMENFASSUNG}

Hintergrund Ziel dieser Studie war es, die retinale Mikrozirkulation in von der Coronavirus-Krankheit 2019 (COVID-19) betroffenen Patienten mithilfe der optischen Kohärenztomografieangiografie (OCT-A) zu untersuchen und mit den Ergebnissen von gesunden Kontrollpersonen zu vergleichen. 
Methoden In der Studie wurden 39 Patienten, die sich vollständig von der Coronavirus-Krankheit erholt hatten, und 40 gesunde Kontrollpersonen untersucht. Zur OCT-A-Bildakquisition wurde die AngioVue-Software (Version 2017.1.0.151) und das RTVue-XR-Avanti-Bildgebungssystem (Optovue Inc., Fremont, CA, USA) verwendet. Das FAZ-Bewertungstool ermittelt automatisch den Non-Flow-Bereich im oberflächlichen Kapillarplexus (SCP), im Bereich der fovealen avaskulären Zone (FAZ) und im gesamten retinalen Gefäßsystem sowie den FAZ-Perimeter, den FAZ-Azirkularitätsindex und die foveale Dichte. Die Gefäßdichte (VD) im SCP und im tiefen Kapillarplexus wurde auch gemessen.

Ergebnisse Auch wenn kein statistisch signifikanter Unterschied beobachtet wurde, war der Non-Flow-Bereich und der FAZ-Bereich in der gesamten Netzhaut in der COVID-19-Grup- pe größer im Vergleich zur Kontrollgruppe (jeweils $p>0,05$ ). Bezüglich der Gefäßdichten waren alle oberflächlichen parafovealen VD-Parameter in der COVID-19-Gruppe erheblich höher im Vergleich zur Kontrollgruppe (jeweils $p<0,05$ ). Obwohl die Gefäßdichten in den verbleibenden Zonen in der COVID-19-Gruppe niedriger waren, waren diese Unterschiede statistisch nicht signifikant (jeweils p > 0,05).

Schlussfolgerung Die VD im parafovealen Bereich des SCP war bei Patienten im späten Rekonvaleszenzstadium der Coronavirus-Erkrankung signifikant höher verglichen mit gesunden Kontrollen. Diese Ergebnisse zeigen die Auswirkungen von COVID-19 auf die retinale Mikrovaskulatur und ihre mögliche Rolle als Risikofaktor für die Entwicklung von Augenerkrankungen auf.

\section{Introduction}

In December 2019, China reported an outbreak of a severe acute respiratory pneumonia, caused by a beta coronavirus strain, severe acute respiratory syndrome coronavirus 2 (SARS-CoV-2) [1]. The illness was termed coronavirus disease 2019 (COVID-19) [1]. The disease soon began to spread to other countries, prompting the World Health Organization to declare COVID-19 a public health emergency and issue recommendations for the prevention of the transmission of SARS-CoV-2.

To date, it has been shown that humans can be infected by seven types of coronavirus, with SARS-CoV-2 being the most recent [2]. Most of the clinical manifestations of coronaviruses occur in the respiratory tract and gastrointestinal system $[3,4]$. Coronaviruses have also been associated with conjunctivitis in humans [5]. Moreover, retinal disorders, including retinal vasculitis $[6,7]$, retinal degeneration $[8,9]$, and blood-retinal barrier breakdown [10], have been reported in experimental animal models of coronavirus infection. However, the ophthalmological complications of SARS-CoV-2 infection have not been well described in human ocular structures.

Optical coherence tomography angiography (OCT-A) is an advance in retinal imaging technology that allows clinicians to assess retinal blood vessel density (VD) and the flow of macular capillary plexuses in humans both quantitatively and qualitatively using a contrast-free technique [11]. Furthermore, OCT-A can provide three-dimensional macular perfusion maps $[11,12]$. Recently, retinal vascular abnormalities have been detected with OCT-A in the early post-recovery phase of COVID-19 [13-15].

The aim of this study was to assess retinal microcirculation in patients in the late post-recovery period of confirmed COVID-19 compared to healthy controls, using OCT-A to better understand the ocular characteristics of COVID-19 patients as well as the clinical course of COVID-19-related ophthalmic complications.

\section{Methods}

This prospective cross-sectional study was conducted in a tertiary hospital. The study is compatible with the tenets of the Declara- tion of Helsinki and was approved by the local ethics committee. All of the study participants received oral and written information about the study protocol and provided written informed consent.

The study recruited patients in the late post-recovery phase of COVID-19 who had been discharged from the isolation ward of the hospital and had recovered enough to return home. All participants had a confirmed diagnosis of COVID-19 (based on a positive real-time reverse transcriptase-polymerase chain reaction [\{RT-PCR $\}]$ test of respiratory specimens) and tested negative after hospitalization. The ophthalmologic examination was carried out after at least 90 days. A control group was created from age- and sex-matched healthy subjects attending the ophthalmology clinic for a routine ocular examination. Those with negative PCR results in the last 3 days were included in the control group. All of the control subjects were healthy and had no systemic or ocular diseases. Data was analyzed from only the right eye of each study participant.

Patients with the following conditions were excluded from the study: presence of any retinal or chorioretinal disease, macular edema, a history of any systemic disorder such as diabetes mellitus, previous ocular surgery or laser photocoagulation, a history of ocular trauma, glaucoma, usage of a topical corticosteroid within six months of study enrollment, anterior segment opacities, or a refractive error of $6 \mathrm{D}$ or more. Only images with a signal strength index (SSI) of 8.0 or greater were included in the study. Poor-quality OCT-A images due to eye movements, poor fixation, or media opacities were also excluded.

All study participants underwent a complete ophthalmological examination prior to OCT-A examination. This included best corrected visual acuity testing via the Snellen chart $(6 \mathrm{~m})$, intraocular pressure measurements using a pneumotonometer, ocular surface and anterior segment assessment by slit lamp biomicroscopy, and dilated fundus examination.

OCT-A images were acquired using the AngioVue software (Version 2017.1.0.151) with the RTVue XR Avanti imaging system (Optovue Inc., Fremont, CA, USA). All OCT-A scans were carried out by the same experienced clinician (HIA) under the same environmental conditions and at the same time of day (between 9:00 $\mathrm{AM}$ and 12:00 PM). The scans were performed following dilation 


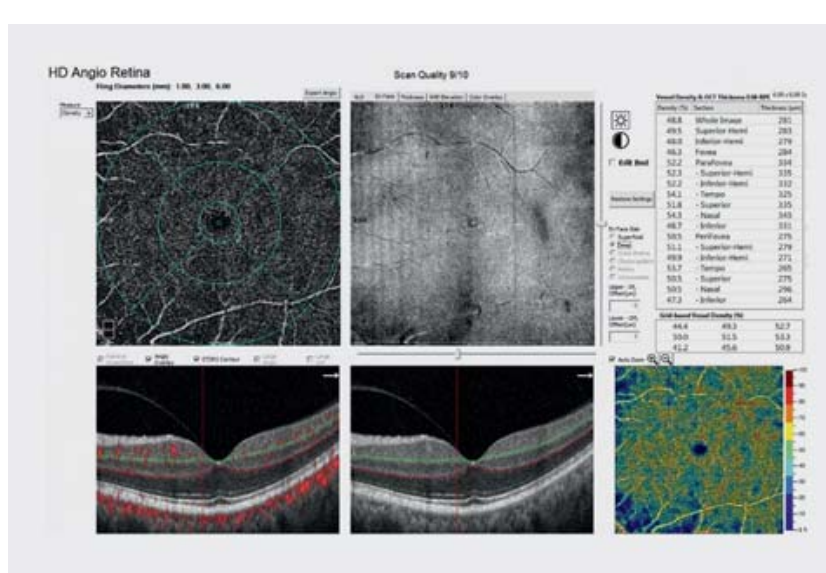

- Fig. 1 Density assessment tool of optical coherence tomography angiography (OCT-A). Superficial (a) and deep (b) capillary plexuses demonstrated by OCT-A. The zones that were automatically divided by the analytic software of the device are shown at the right corner of each figure.
- Table 1 Demographic and ocular characteristics of the participants.

\begin{tabular}{|l|l|l|l|}
\hline & $\begin{array}{l}\text { COVID-19 } \\
\text { Group (n=39) }\end{array}$ & $\begin{array}{l}\text { Control Group } \\
(\mathbf{n = 4 0 )}\end{array}$ & P value \\
\hline $\begin{array}{l}\text { Age } \\
\text { (years) }\end{array}$ & $45.23 \pm 13.20$ & $47.60 \pm 12.14$ & $0.540^{*}$ \\
\hline $\begin{array}{l}\text { BCVA } \\
\text { (Snellen) }\end{array}$ & $0.91 \pm 0.07$ & $0.92 \pm 0.06$ & $0.776^{*}$ \\
\hline $\begin{array}{l}\text { IOP, } \\
\text { mmHg }\end{array}$ & $13.05 \pm 2.39$ & $13.27 \pm 2.84$ & $0.707^{*}$ \\
\hline $\begin{array}{l}\text { Sex (male/ } \\
\text { female) }\end{array}$ & $20 / 19$ & $18 / 22$ & $0.736^{*}$ \\
\hline $\begin{array}{l}\text { Refractive } \\
\text { error (D) }\end{array}$ & $-1.11 \pm-0.45$ & $-1.22 \pm-0.33$ & $0.782^{*}$ \\
\hline
\end{tabular}

BCVA: best corrected visual acuity, IOP: intraocular pressure, D: diopter ${ }^{*}$ Independent samples test. ${ }^{*}$ Chi-square test.

ment tool. Moreover, the FAZ assessment tool automatically determined the FAZ area in the whole retinal vasculature, FAZ perimeter, acircularity index (AI) of FAZ, and foveal density (FD-300). AI is defined as the ratio of the perimeter of the FAZ and the perimeter of a circle with an equal area. A vessel density of $300 \mathrm{~mm}$ around the FAZ is known as FD-300.

The following parameters were compared between the COVID19 and control groups: FAZ area of the entire retina, nonflow area in the SCP, FAZ perimeter, AI, FD-300, and the VD values for the SCP and DCP in the foveal, parafoveal, and perifoveal zones.

\section{Statistical analysis}

All data were analyzed using SPSS version 22.0 (IBM, Armonk, NY, USA). Descriptive statistics are presented as mean \pm standard deviations. Both Pearson's chi-squared test and one sample chisquared test were used to compare categorical variables between the COVID-19 and control groups. The Kolmogorov-Smirnov test was used to ensure normal distribution of the data. Independent sample t-tests were used for normally distributed data and the Mann-Whitney $U$ test was used for non-normally distributed data to classify the COVID-19 group and the control group. P-values $<0.05$ were considered statistically significant.

\section{Results}

The current study included data from 79 eyes belonging to 79 subjects: 39 in the late post-recovery phase of COVID-19 and 40 healthy controls. There were no significant differences between the two study groups with regard to age or sex ( $p>0.05$ respectively). Demographic and ocular characteristics of both groups are summarized in $>$ Table 1 .

Comparisons of the FAZ and macular VD parameters between the two study groups are presented in $>$ Table 2 . Both the nonflow area and the FAZ area of the entire retina were larger in the COVID-19 group compared to the control group; however, these differences were not statistically significant $(p>0.05$ respective- 
- Table 2 Comparison of the FAZ and macular vessel density assessment tool parameters in different sections.

\begin{tabular}{|c|c|c|c|}
\hline & COVID-19 Group ( $n=39$ ) & Control Group $(n=40)$ & P value* \\
\hline Nonflow area $\left(\mathrm{mm}^{2}\right) \mathrm{SCP}$ & $0.51 \pm 0.10$ & $0.50 \pm 0.12$ & 0.51 \\
\hline FAZ area $\left(\mathrm{mm}^{2}\right)$ whole retina & $0.29 \pm 0.09$ & $0.28 \pm 0.11$ & 0.70 \\
\hline FAZ perimeter (mm) & $2.06 \pm 0.33$ & $2.01 \pm 0.45$ & 0.51 \\
\hline Acircularity index & $1.07 \pm 0.15$ & $1.09 \pm 0.02$ & 0.32 \\
\hline Foveal density (\%) & $55.86 \pm 3.42$ & $55.54 \pm 4.34$ & 0.72 \\
\hline \multicolumn{4}{|l|}{ Vessel density, SCP flow (\%) } \\
\hline Whole retina & $51.18 \pm 2.90$ & $51.74 \pm 2.21$ & 0.34 \\
\hline - Superior hemisphere & $51.00 \pm 2.92$ & $51.71 \pm 2.12$ & 0.21 \\
\hline - Inferior hemisphere & $51.37 \pm 2.93$ & $51.76 \pm 2.40$ & 0.51 \\
\hline - Fovea & $19.54 \pm 6.40$ & $20.08 \pm 6.32$ & 0.70 \\
\hline - Parafovea & $55.50 \pm 3.13$ & $53.18 \pm 2.59$ & 0.04 \\
\hline - Superior hemisphere & $55.39 \pm 3.36$ & $53.04 \pm 2.66$ & 0.04 \\
\hline - Inferior hemisphere & $55.60 \pm 3.09$ & $53.13 \pm 2.82$ & 0.04 \\
\hline - Temporal & $55.82 \pm 3.56$ & $53.08 \pm 2.76$ & 0.03 \\
\hline " Superior & $56.20 \pm 3.62$ & $54.03 \pm 3.04$ & 0.04 \\
\hline - Nasal & $55.94 \pm 3.39$ & $53.15 \pm 2.66$ & 0.02 \\
\hline - Inferior & $56.03 \pm 3.19$ & $54.07 \pm 3.25$ & 0.03 \\
\hline Perifovea & $51.83 \pm 3.07$ & $52.43 \pm 2.28$ & 0.33 \\
\hline - Superior hemisphere & $51.62 \pm 3.10$ & $52.40 \pm 2.15$ & 0.19 \\
\hline - Inferior hemisphere & $52.04 \pm 3.16$ & $52.43 \pm 2.54$ & 0.54 \\
\hline - Temporal & $48.21 \pm 2.83$ & $48.68 \pm 2.25$ & 0.41 \\
\hline - Superior & $51.23 \pm 3.77$ & $52.54 \pm 2.47$ & 0.07 \\
\hline - Nasal & $54.47 \pm 8.61$ & $55.93 \pm 2.38$ & 0.30 \\
\hline - Inferior & $51.94 \pm 3.81$ & $52.56 \pm 2.87$ & 0.42 \\
\hline \multicolumn{4}{|l|}{ Vessel density, DCP flow (\%) } \\
\hline Whole retina & $52.47 \pm 5.01$ & $53.53 \pm 5.02$ & 0.35 \\
\hline Superior hemisphere & $52.52 \pm 5.22$ & $53.60 \pm 5.18$ & 0.36 \\
\hline Inferior hemisphere & $52.41 \pm 4.94$ & $53.53 \pm 5.04$ & 0.32 \\
\hline Fovea & $37.06 \pm 6.82$ & $38.14 \pm 7.95$ & 0.52 \\
\hline Parafovea & $55.80 \pm 4.62$ & $56.95 \pm 3.76$ & 0.22 \\
\hline - Superior hemisphere & $56.15 \pm 4.31$ & $57.13 \pm 3.82$ & 0.29 \\
\hline - Inferior hemisphere & $56.20 \pm 3.96$ & $56.81 \pm 3.81$ & 0.49 \\
\hline - Temporal & $56.78 \pm 4.07$ & $58.00 \pm 3.88$ & 0.18 \\
\hline - Superior & $55.65 \pm 4.23$ & $56.46 \pm 3.95$ & 0.38 \\
\hline - Nasal & $57.21 \pm 4.17$ & $57.70 \pm 3.54$ & 0.58 \\
\hline - Inferior & $55.58 \pm 3.77$ & $55.70 \pm 4.48$ & 0.89 \\
\hline Perifovea & $54.19 \pm 5.33$ & $55.44 \pm 5.32$ & 0.30 \\
\hline - Superior hemisphere & $54.24 \pm 5.49$ & $55.54 \pm 5.48$ & 0.29 \\
\hline - Inferior hemisphere & $54.13 \pm 5.32$ & $55.36 \pm 5.40$ & 0.31 \\
\hline - Temporal & $55.11 \pm 8.97$ & $57.80 \pm 3.90$ & continued \\
\hline
\end{tabular}


- Table 2 Continued

\begin{tabular}{|l|l|l|l|}
\hline & COVID-19 Group (n= 39) & Control Group (n= 40) & P value* \\
\hline - Superior & $53.21 \pm 6.22$ & $55.01 \pm 6.21$ & 0.20 \\
\hline - Nasal & $53.27 \pm 6.49$ & $53.53 \pm 6.14$ & 0.85 \\
\hline - Inferior & $53.72 \pm 5.86$ & $55.18 \pm 6.26$ & 0.28 \\
\hline
\end{tabular}

DCP: deep capillary plexus; SCP: superficial capillary plexus; * Independent samples t-test (differences between COVID-19 group and controls). Bold values indicate statistical significance, $\mathrm{p}<0.05$.
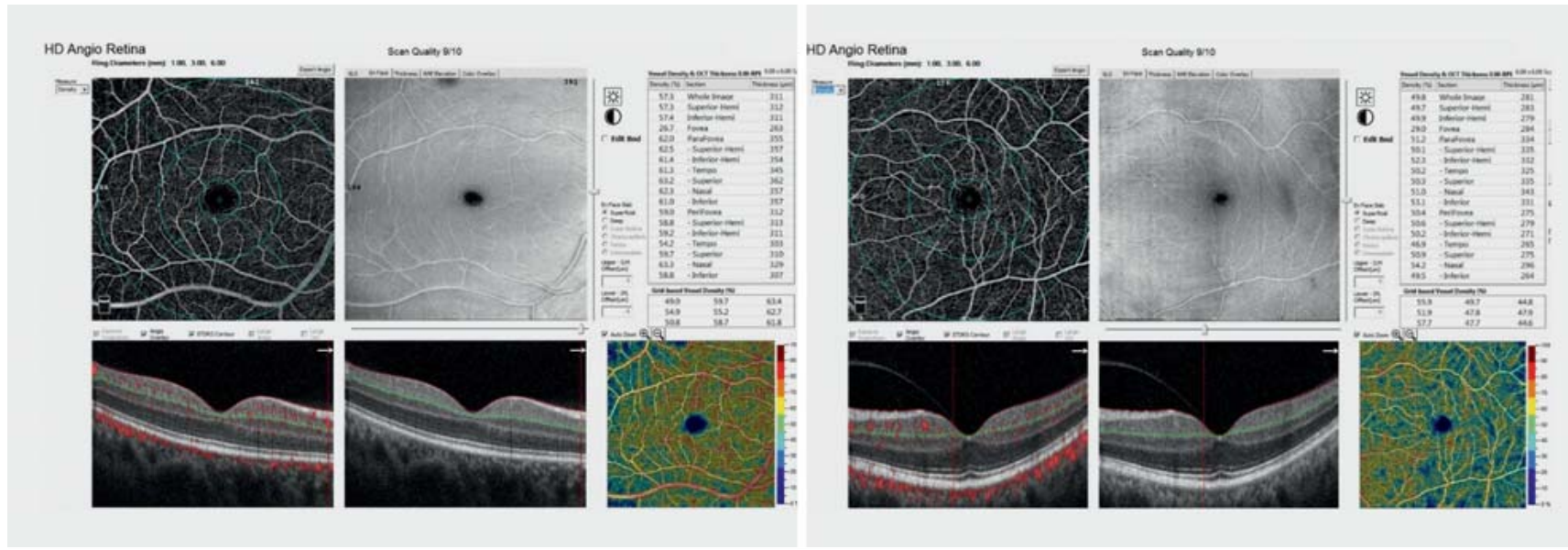

- Fig. 2 All superficial parafoveal VD parameters in the late post-recovery period were statistically considerably higher compared to controls.

ly). As for vessel densities, all superficial parafoveal VD parameters were significantly higher in the COVID-19 group compared to the control group, as illustrated in $>$ Fig. 2 ( $p<0.05$ respectively). The VDs in the remaining zones were lower in the COVID-19 group compared to the control group, but these differences were not statistically significant ( $p>0.05$ respectively).

\section{Discussion}

Even though a long time has passed since the emergence of the COVID-19 pandemic, the effects of the virus on various organ systems are still being investigated. Although COVID-19 is most often associated with acute respiratory distress syndrome, its apparent link to conjunctivitis has sparked the interest of ophthalmologists [16]. The fact that the ACE2 receptor used by SARSCoV-2 for invasion is present in many ocular tissues also suggests that the virus may have an impact on all ocular tissues [17-21].

In animal models, the ACE2 receptor has been identified in the ciliary body, the vitreous body, and in the inner nuclear layer of the retina, particularly in the Müller cells [22]. A recent study in postmortem COVID-19 patients reported the presence of viral RNA in the retina [23]. Moreover, in an OCT/OCT-A study of 12 patients 11-33 days after the onset of COVID-19 symptoms, Marinho et al. reported cotton-wool spots and microhemorrhages in 4 patients on OCT, suggestive of an inner retinal ischemic process [24]. On the other hand, the researchers did not observe any changes with OCT-A [24]. However, a subsequent editorial letter indicated that these findings represented normal vascular landmarks [25]. Overall, the ophthalmologic effects of COVID-19 should be evaluated in further quantitative studies with a large number of subjects. OCT-A is a new, non-invasive imaging technique that provides volumetric data and has the clinical capability to specifically localize and delineate pathologies along with the ability to show both structural and blood flow information [26]. With this in mind, we compared quantitative FAZ and macular VD parameters obtained by OCT-A from people who had recovered from COVID-19 and from healthy controls.

The effect of COVID-19 on vascular structures and FAZ parameters in the retina has been addressed in several studies [13-15]. Savastano et al. [13] detected reduced perfusion density of the radial peripapillary capillary plexus in recovered COVID-19 patients compared to age-matched controls using OCT-A analysis. Abrishami et al. [14] reported reduced vessel density in the SCP and DCP of the foveal and parafoveal regions in recovered COVID-19 patients within two weeks of seronegativity compared to healthy controls. Additionally, the recovered COVID-19 patients had larger FAZ areas, but this was not statistically significant [14]. Turker et al. evaluated vascular changes in the early period after moderate COVID-19 infection and at 6-month follow-up and found lower VD values than for control subjects in all parafoveal quadrants of both the SCP and DCP at the initial checkup and in all parafoveal quadrants of the SCP and in 2 of the parafoveal 
quadrants of the DCP at 6-month follow-up [27]. In a recent study, Cennamo et al. showed a significant reduction in the VD of the SCP in whole images and in the DCP in all sectors when they compared post-SARS-CoV-2 pneumonia patients with healthy subjects [28]. In another study, people with moderate and severe COVID-19 examined within 3 months of RT-PCR positivity showed decreased central retinal VD compared to people with asymptomatic COVID-19 and healthy controls [15].

In our study, the nonflow area and the FAZ area situated in the entire retina were slightly larger in the group of people with COVID-19 compared to the controls, but these differences were not statistically significant. These results are in line with the findings of Abirashimi et al. [14] for the early post-recovery phase of COVID-19. The fact that we found consistent results in the postrecovery period of COVID-19 may indicate that SARS-CoV-2 infection causes a chronic ischemic process in the retina. Moreover, changes of the FAZ might only be a transient effect related to the acute phase of the disease. Of course, these findings should be evaluated in larger cohort studies, as the results reported here are not statistically significant. It is also possible that the differences in FAZ we and Abirashimi et al. reported may simply reflect differences in retinal vasculature among individuals, with no relation to COVID-19.

When we evaluated the VD at both the SCP and DCP, only the parafoveal VD at the SCP was significantly higher in the COVID-19 group compared to the control group. The VD in the remaining sections was lower in the COVID-19 group, but these differences were not statistically significant. Although other studies have reported a decrease in retinal VD in people with COVID-19 [14, 15], we observed an increase in parafoveal VD at the SCP. These differences could be explained by inflammation and ischemia triggered by invasion of the virus in the early post-recovery period. It is known that the parafoveal region plays an important role in supplying the macula [11-12], and our reported findings could reflect a compensatory mechanism aimed at protecting the macular area from the ischemic process of SARS-CoV-2 infection during the late post-recovery period, thereby resulting in an increase in parafoveal VD at the SCP. It should be noted that the participants in other studies were patients who had moderately severe or very severe disease. Since our study group consisted of people who had mild COVID-19, this may explain the low but not significant VD values.

This study is the first to quantify macular VD and FAZ parameters in patients with mild COVID-19 during the late post-recovery period. However, like all other studies, our study has certain limitations. First, our sample size was relatively small. Accordingly, these findings need to be confirmed in a much larger cohort study of COVID-19 patients from multiple centers. Second, our study did not assess the long-term evolution of macular VD and FAZ parameters, and this should also be evaluated in future studies. Another drawback of our study was the use of chloroquine and hydroxychloroquine to treat COVID-19 (400 mg/day). Chloroquine/ hydroxychloroquine is associated with an elevated risk of retinopathy at high doses. However, retinopathy is rarely seen before 10 or more years of chloroquine/hydroxychloroquine usage at doses of $<5 \mathrm{mg} / \mathrm{kg}[29,30]$. But the use of higher dosages has been reported to affect the retina after 11 to 17 months [30].
Therefore, given the short-term nature of our study, we believe our findings only reflect the effect of COVID-19 on the retina. Moreover, the changes detected with OCT-A are not specific to COVID-19 but can be seen with other viral agents. Therefore, although this issue is a limited aspect of our study, it should be evaluated in future studies.

To conclude, the inflammatory process of COVID-19 could affect retinal vascular structures in the late post-recovery period. While the FAZ parameters were stable among people with COVID-19 in our study, the VD in the parafoveal area at the SCP was significantly higher compared to healthy controls. Long-term follow-up studies in a large group of patients are needed to confirm these results.

\section{Conflict of Interest}

The authors declare that they have no conflict of interest. There was no funding to support this study.

\section{References}

[1] Wang C, Horby PW, Hayden FG et al. A novel coronavirus outbreak of global health concern. Lancet 2020; 395: 470-473

[2] Corman VM, Muth D, Niemeyer D et al. Hosts and sources of endemic human coronaviruses. Adv Virus Res 2018; 100: 163-188

[3] Shi X, Gong E, Gao D et al. Severe Acute Respiratory Syndrome Associated Coronavirus Is Detected in Intestinal Tissues of Fatal Cases. Am J Gastroenterol 2005; 100: 169-176

[4] Paules $\mathrm{Cl}$, Marston HD, Fauci AS. Coronavirus Infections-More Than Just the Common Cold. JAMA 2020; 323: 707-708

[5] van der Hoek L, Pyrc K, Jebbink MF et al. Identification of a new human coronavirus. Nat Med 2004; 10: 368-373

[6] Chin MS, Hooper LC, Hooks J] et al. Identification of $\alpha$-fodrin as an autoantigen in experimental coronavirus retinopathy (ECOR). J Neuroimmunol 2014; 272: 42-50

[7] Hooks J], Wang Y, Detrick B. The critical role of IFN-gamma in experimental coronavirus retinopathy. Invest Ophthalmol Vis Sci 2003; 44: 3402-3408

[8] Wang Y, Detrick B, Yu ZX et al. The role of apoptosis within the retina of coronavirus infected mice. Invest Ophthalmol Vis Sci 2000; 41: 30113018

[9] Detrick B, Lee MT, Chin MS et al. Experimental coronavirus retinopathy (ECOR): retinal degeneration susceptible mice have an augmented interferon and chemokine (CXCL9, CXCL10) response early after virus infection. J Neuroimmunol 2008; 193: 28-37

[10] Vinores SA, Wang Y, Vinores MA et al. Blood-Retinal barrier breakdown in experimental coronavirus retinopathy: association with viral antigen, inflammation, and VEGF in sensitive and resistant strains. J Neuroimmunol 2001; 119: 175-182

[11] Spaide RF, Fujimoto JG, Waheed NK et al. Optical coherence tomography angiography. Prog Retin Eye Res 2018; 64: 1-55

[12] Kashani AH, Chen CL, Gahm JK et al. Optical coherence tomography angiography: A comprehensive review of current methods and clinical applications. Prog Retin Eye Res 2017; 60: 66-100

[13] Savastano A, Crincoli E, Savastano MC et al. Peripapillary Retinal Vascular Involvement in Early Post-COVID-19 Patients. J Clin Med 2020; 9: 2895

[14] Abrishami M, Emamverdian Z, Shoeibi N et al. Optical coherence tomography angiography analysis of the retina in patients recovered from COVID-19: a case-control study. Can J Ophthalmol 2020; 56: 24-30 
[15] Zapata MÁ, Banderas García S, Sánchez-Moltalvá A et al. Retinal microvascular abnormalities in patients after COVID-19 depending on disease severity. $\mathrm{Br}$ J Ophthalmol 2020. doi:10.1136/bjophthalmol2020-317953

[16] Wu P, Duan F, Luo C et al. Characteristics of Ocular Findings of Patients with Coronavirus Disease 2019 (COVID-19) in Hubei Province, China. JAMA Ophthalmol 2020; 138: 575-578

[17] Collin J, Queen R, Zerti D et al. Co-expression of SARS-CoV-2 entry genes in the superficial adult human conjunctival, limbal and corneal epithelium suggests an additional route of entry via the ocular surface. Ocul Surf 2020; 19: 190-200

[18] Ma D, Chen CB, Jhanji $V$ et al. Expression of SARS-CoV-2 receptor ACE2 and TMPRSS2 in human primary conjunctival and pterygium cell lines and in mouse cornea. Eye (Lond) 2020; 34: 1212-1219

[19] Zhou L, Xu Z, Castiglione GM et al. ACE2 and TMPRSS2 are expressed on the human ocular surface, suggesting susceptibility to SARS-CoV-2 infection. Ocul Surf 2020; 18: 537-544

[20] Senanayake Pd, Drazba J, Shadrach K et al. Angiotensin II and its receptor subtypes in the human retina. Invest Ophthalmol Vis Sci 2007; 48: 3301-3311

[21] Holappa M, Valjakka J, Vaajanen A. Angiotensin (1-7) and ACE2, "The Hot Spots" of Renin-Angiotensin System, Detected in the Human Aqueous Humor. Open Ophthalmol J 2015; 9: 28-32

[22] Luhtala S, Vaajanen A, Oksala O et al. Activities of angiotensin-converting enzymes ACE1 and ACE2 and inhibition by bioactive peptides in porcine ocular tissues. J Ocul Pharmacol Ther 2009; 25: 23-28
[23] Casagrande M, Fitzek A, Püschel K et al. Detection of SARS-CoV-2 in Human Retinal Biopsies of Deceased COVID-19 Patients. Ocul Immunol Inflamm 2020; 28: 721-725

[24] Marinho PM, Marcos AAA, Romano AC et al. Retinal findings in patients with COVID-19. Lancet 2020; 395: 1610

[25] Vavvas DG, Sarraf D, Sadda SR et al. Concerns about the interpretation of OCT and fundus findings in COVID-19 patients in recent Lancet publication. Eye (Lond) 2020; 34: 2153-2154

[26] de Carlo TE, Romano A, Waheed NK et al. A review of optical coherence tomography angiography (OCTA). Int J Retina Vitreous 2015; 1: 5

[27] Turker IC, Dogan CU, Dirim AB et al. Evaluation of Early and Late COVID-19-Induced Vascular Changes with Optical Coherence Tomography Angiography. Can J Ophthalmol 2021. doi:10.1016/j.jcjo.2021. 05.001

[28] Cennamo G, Reibaldi M, Montorio D et al. Optical Coherence Tomography Angiography Features in Post-COVID-19 Pneumonia Patients: A Pilot Study. Am J Ophthalmol 2021; 227: 182-190

[29] Marmor MF. COVID-19 and Chloroquine/Hydroxychloroquine: Is There Ophthalmological Concern? Am J Ophthalmol 2020; 216: A1-A2

[30] Goker YS, Ucgul Atılgan C, Tekin K et al. The Validity of Optical Coherence Tomography Angiography as a Screening Test for the Early Detection of Retinal Changes in Patients with Hydroxychloroquine Therapy. Curr Eye Res 2019; 44: 311-315 